\title{
Long-term outcome after anterior cervical discectomy without fusion
}

\author{
Rishi D. S. Nandoe Tewarie • \\ Ronald H. M. A. Bartels · Wilco C. Peul
}

Received: 7 August 2006/Revised: 27 November 2006/ Accepted: 6 January 2007/ Published online: 30 January 2007

(C) Springer-Verlag 2007

\begin{abstract}
To retrospectively study the long-term outcome of patients after anterior cervical discectomy without fusion (ACD) compared to results published on the long-term outcome after ACD with fusion (ACDF). We reviewed the charts of all patients receiving ACD surgery between 1985 and 2000 to analyze the direct post-operative results as well as complications of the surgery. Moreover, 102 patients, randomly selected, were interviewed with the neck disability index to study possible persisting complaints up to 18 years after ACD surgery. A total of $551 \mathrm{~Pa}$ tients were identified. Two months post-operative follow up at the outpatient clinic revealed that $90.1 \%$ of patients were satisfied with the result of ACD surgery. At the time of the survey, this percentage had dropped to $67.6 \%$. In addition, $20.6 \%$ and $11.8 \%$ had obtained moderate to severe complaints, respectively, in dailylife activities. Complaints were mainly localized in the neck region and occasionally provoked radiating pain in the arm. On the short term, ACD leads to a satisfied outcome. Over the longer term, patients report increasing complaints. The increase in complaints at the time of the survey may be the result of ongoing
\end{abstract}

R. D. S. Nandoe Tewarie $(\bowtie) \cdot$ R. H. M. A. Bartels University Medical Center Nijmegen, Neurosurgery, R. Postlaan 4, 6500 HB Nijmegen, Gelderland,

The Netherlands

e-mail: R.D.S.Nandoe@nch.umcn.nl

W. C. Peul

Medical Center Haaglanden, Neurosurgery,

The Hague, South-Holland, The Netherlands

W. C. Peul $(\bowtie)$

Leiden University Medical Center, Neurosurgery,

Leiden, South-Holland, The Netherlands degenerative effects. Compared to published data on $\mathrm{ACDF}$, there is no superiority of any fusion technique compared to ACD alone.

Keywords Cervical · Discectomy · Surgery · Outcome

\section{Introduction}

Cervical spondylosis and disk herniation are frequent causes of arm pain. When conservative treatment fails, surgical decompression can be considered. The most common surgical techniques are discectomy with or without fusing the two adjacent intervertebral bodies. Robinson and Smith [3, 33, 34, 38] introduced the anterior cervical decompression technique without microscope, but with fusion by inserting a bone graft harvested from the iliac crest of the patient. Hankinson and Wilson [18] improved the procedure with the use of an operating microscope; however, they performed the surgery without leaving a graft behind; the results of both types of surgery were entirely comparable $[1,12,20]$.

In time several modifications of these surgical techniques have been made $[6,10,28]$. In addition, to enhance fusion, anterior plating procedures have been developed. These plating procedures provide immediate stability and maintain spinal alignment $[20,22]$. The outcome of these studies has ranged from no significant improvement in clinical outcome $[22,40]$ to increased fusion rates and fewer re-operations possibly due to the stabilizing effects of plating [9, 23, 44, 45]. Finally, more recently, artificial intervertebral disc replacements have been used to try to simulate the natural 
situation and motion of the spinal column [8]. Although the first results have been promising [16, 26], some have presented cases in which as adverse effect fusion around the prosthesis occurred [5].

Performing anterior cervical discectomy with fusion (ACDF) has proven to be successful in relieving arm pain and has been considered as the golden standard for this kind of surgery. However, ACDF has not been proven to be better than anterior cervical discectomy without fusion (ACD) [20]. Especially, in Europe ACD alone is still being used as a surgical procedure. In this study, we retrospectively study the long-term clinical outcome after ACD surgery and compare this with the long-term outcome of ACDF surgery as reported in literature.

\section{Materials and methods}

The database of the neurosurgical department of Leiden University Medical Center (LUMC), Leiden, The Netherlands, was searched for patients on whom single level ACD surgery was performed between 1985 and 2000. All patients' charts were studied for level and side of surgery, pre operative symptoms, post operative results, possible complications and follow up at the outpatient clinic. At random, 102 patients were subjected to a survey by phone concerning their complaints at that time using the Neck Disability Index (NDI) [42]. Patients from all years of the study were included. The questionnaire consisted of ten questions, each containing six statements (A-F). The sections concerned impairments like pain and abilities like personal care, lifting, reading, driving, and recreation. For each section, subjects choose the statement that best described their status. The chosen statements received scores: statement $\mathrm{A}=0$; statement $\mathrm{B}=1$; $\mathrm{C}=2 ; \mathrm{D}=3 ; \mathrm{E}=4 ; \mathrm{F}=5$. Total scores ranged from 0 (highest level of function) to 50 (lowest level of function). We used the Fairbank et al. [13] grading system to grade the patients' outcome at the time of the survey. According to Fairbank et al. [13] clinicians can calculate the "percentage of disability" with scores of 0-10 for minimal disability. Scores ranging from 10 to 20 stands for moderate disability in which patients are comprised in their daily activities; however they manage to balance their activities in relation to the complaints. More than 20 points is considered to give restrictions in daily care and result in patients needing to stop certain activities because of their neck complaints and are graded severe.

Patients with moderate to severe complaints were also analyzed by sorting them according to the year they received ACD surgery. The follow-up period at the time of the survey was then calculated by subtracting the year of the surgery from the year of the survey. Finally, the average NDI score at the time of the survey was related to these follow-up periods to study the correlation between complaints and time after surgery.

Discharge from the hospital usually occurred the day after surgery, unless patients complained about severe dysphagia with minimal oral intake or complications occurred. First follow up at the outpatient clinic was done 6 weeks after surgery.

\section{Surgical technique}

Patients were operated by several surgeons joining the neurosurgical team at the LUMC. Nevertheless, all surgeons performed ACD surgery as previously described [36] in the same manner. Briefly, a transverse incision is being used. Using optical magnification and by passing medially from the carotid sheath and laterally from the esophagus and trachea, the anterior aspect of the cervical spine can be reached. After identification of the correct level, the anterior longitudinal ligament is cut and the intervertebral disc excised. Finally, the endplates are removed from the cartilage to induce fusion.

\section{Results}

A total of 551 patients were identified, of which 324 were men and 227 women. The age ranged between 17 and 84 years. We were able to retrieve 456 of the 551 charts of the patients. The level of surgery is depicted in Table 1.

Pre-operatively, $41.2 \%(n=190)$ of the patients had pain in the right arm, $48.9 \%(n=223)$ in the left, while $9.9 \%(n=43)$ either had pain in both arms or did not have a clear radiating pain in an arm. Next to the radiating pain, $19.6 \%(n=89)$ had this in combination with (subjective) motor deficits and $7.1 \%(n=32)$ had complaints of myelopathia.

Post-operatively, complications occurred in $10.5 \%$ $(n=48)$, ranging from minor complications including urinary tract infections and pneumonia in $3.7 \%$ $(n=17)$ to more severe complications resulting in a second operation and an increased hospital stay such as progressive neurological loss $(0.7 \%, n=3)$ or a hematoma $(0.9 \%, n=4)$. Hoarseness occurred in $2.2 \%$ $(n=10)$ (Table 2).

Follow-up at the outpatient clinic 6 weeks after surgery revealed that $90.1 \%(n=411)$ of patients were 
Table 1 Level of surgery $(n=456)$

\begin{tabular}{ll}
\hline C2-C3 & $0 \%(n=0)$ \\
C3-C4 & $2.0 \%(n=9)$ \\
C4-C5 & $5.9 \%(n=27)$ \\
C5-C6 & $40.1 \%(n=183)$ \\
C6-C7 & $47.8 \%(n=218)$ \\
C7-Th1 & $4.2 \%(n=19)$ \\
\hline
\end{tabular}

$C$ cervical, $T h$ thoracic

Table 2 Complications (out of $n=456$ )

\begin{tabular}{ll}
\hline Increased neurological deficits & $0.7 \%(n=3)$ \\
Hoarseness & $2.2 \%(n=10)$ \\
Hematoma & $0.9 \%(n=4)$ \\
Re-operation & $3.1 \%(n=14)$ \\
Others & $3.7 \%(n=17)$ \\
Total & $10.5 \%(n=48)$ \\
\hline
\end{tabular}

satisfied with the surgery, although regularly numbness of the top of the digits persisted. In $9.9 \%(n=43)$ patients' complaints remained as existed pre-operatively.

At the time of the survey, the post-operative followup period of the patients $(n=102)$ differed from 3 years up to 18 years, with a median and mean of 7 years. The NDI [42] revealed that in $67.6 \%(n=69)$ of the patients, complaints had not returned and new neck complaints had not occurred. Furthermore, $20.6 \%(n=21)$ of patients had moderate complaints in the neck, which allowed them to continue their daily activities with some adaptations. Finally, $11.8 \%(n=12)$ had severe complaints such as pain in neck and head, problems in daily personal care, reading and driving difficulties and had to stop certain activities (Table 3 ).

Patients with a good outcome were found at all follow up periods, without a clear preference (Fig. 1). Evaluation of the moderate and severe complaints in time showed that this group of patients increased their complaints in time after surgery. Figure 1 shows a graph of the average NDI score for each year of surgery. In Table 4, the mean NDI score has been calculated in brackets of 5-year follow-up. The table does not show a clear deterioration in complaints over time, however, by adding a trend line in the graph it becomes

Table 3 Neck disability score of $n=102$ patients

\begin{tabular}{lcll}
\hline Score & Patients & Score & Patients \\
\hline 0 & 44 & $21-25$ & 5 \\
$1-5$ & 18 & $26-30$ & 4 \\
$6-10$ & 7 & $31-35$ & 1 \\
$11-15$ & 12 & $36-40$ & 1 \\
$16-20$ & 9 & $41-45$ & 1 \\
\hline
\end{tabular}

clear that there is an increase in complaints with an increase of follow-up time after surgery. The line drops 10 points in NDI score over the 15 years of follow up, which means that each year an increase of 0.67 points in complaints can be estimated (Fig. 1 and Table 4).

\section{Discussion}

Literature and medical technology have focused on different fusion techniques in ACD surgery [2, 17]. Several groups report their results of ACDF using different techniques: allograft, autograft, cages with different designs and plating dynamic or not, with as most important outcome that the use of autograft is superior to allograft and that the postoperative neckpain after surgery is relieved quicker after ACDF [6, $27,28,30]$. Only a few studies have compared ACD alone with fusion techniques and they all do not show any superiority of a fusion method compared to ACD without fusion $[1,11,12,20,29,30]$. Avoidance of the use of implants reduces costs of surgery. More importantly, these studies revealed that ACD alone resulted in a shorter surgery procedure, hospital stay and sick leave $[1,12,35]$. A frequently reported complication of autologous grafting from the iliac crest is post-operative pain at the donor site, which has been reported to result in up to $22 \%$ additional morbidity [30]. Although a more elegant needle technique has reduced this percentage, at 2 weeks post-operatively $12 \%$ of patients still has persisting complaints of pain at the donor site [4]. Other complications include wound hematoma, infection, pelvic fracture and nerve palsy at the donor site region [20]. An alternative to prevent this morbidity is the use of allografts [37, 41, 43]. Unfortunately, allografts are expensive, incorporate more slowly and carry the potential risk of disease transmission [20] (Table 5).

In this study, $2.2 \%$ of patients had complaints of hoarseness direct post-operative. It has been reported that this percentage is approximately $5 \%$ after ACDF [31] (Table 5). Although $80 \%$ of vocal cord paralysis recovers within 12 months, this is an invalidating complication for the patient.

Sagittal profiles of the spinal cord have been hypothesized to influence loads on spinal tissue and influence outcome after spinal surgery [24, 25]. It is believed that ACDF surgery maintains sagittal alignment superiorly to ACD surgery, which should result in a better outcome after surgery and thus on the long term in less disability for the patients. Studies on sagittal alignment in the cervical spine have mainly focused on laminoplasty or arthroplasty [21, 25] showing 


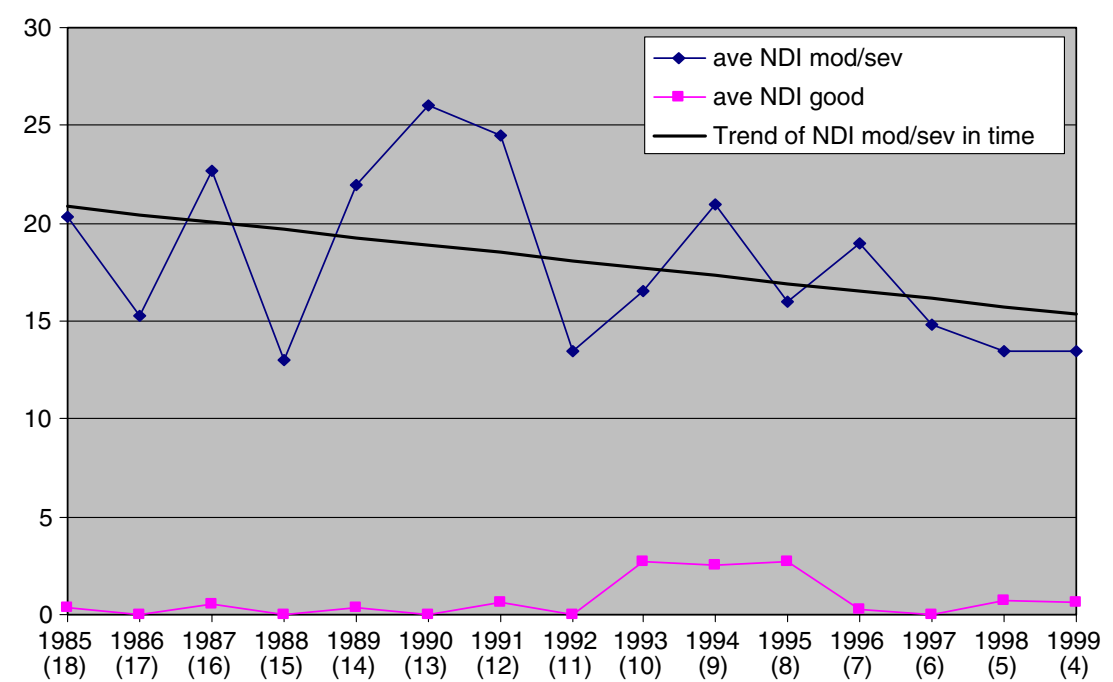

Fig. 1 Average neck disability scores of patients with good or moderate to severe outcomes at the time of the survey related to the year of surgery. In blue the average scores of moderate to severe patients for each year of surgery between 1985 and 2000 and in black a trend line was added to reveal an increase in complaints after a longer follow up period after single level anterior cervical spine surgery. In pink the average scores of patients with a good outcome. Between brackets are the total years of follow up at the time of the survey

Although, initially the postoperative outcome is good in more than $90 \%$ of the patients, the outcome score on the longer term gradually decreased as the follow up time after surgery increased in a subgroup of the patients. Patients who are doing well after surgery are found without a significant difference at all time points, however patients with moderate to severe complaints can be found increasingly in time after surgery. The increase of complaints at the time of the survey may be the result of ongoing degenerative effects. Only a few studies have been published focusing on a long follow-up period after cervical spine procedures compared to ACDF and therefore it is hard to address the ongoing degenerative effects in the cervical spine. The few that are published have mainly focused on posterior foraminotomy without fusion compared to ACDF, demonstrating similar rates of adjacent segment disease with an annual incidence of $2-3 \%$ [19]. Additionally, the increase in complaints is in accor-
Table 5 Characteristics of each surgical procedure

$A C D$ anterior cervical discectomy, $A C D F$ anterior cervical discectomy with fusion

\begin{tabular}{ll}
\hline ACD & ACDF \\
\hline Similar outcome to ACDF on long term & Similar outcome to ACD on long term \\
Lower risk hoarseness $(2.2 \%$ versus $5 \%)$ & Quicker neck pain relief after surgery \\
No additional morbidity of a donor site & Better sagittal alignment \\
Lower costs & Additional morbidity: pain at donor site \\
Shorter length surgical procedure & Possible complications at donor site \\
Shorter hospital stay & (Hematoma, infection, pelvic fracture) \\
\hline
\end{tabular}


dance with the outcome scores after different spine surgeries $[7,14,15]$.

\section{Conclusion}

Since the complication rate is higher with ACD surgery combined with fusion using autologous material or more expensive in case of the use of alternatives to autologous bone, fusion should at least offer minimal advantages on the long term. Our results show that ACD surgery is certainly not inferior to the results of ACDF. In fact they are comparable. Because the superiority of any fusion procedure has never been proven, it has been suggested that fusion might not be necessary at all $[12,39]$. Although, initially the postoperative outcome is good, over the longer term the patients report increasing complaints. Taking into consideration that the long-term complaints may well be the result of ongoing degenerative disc disease, a prospective randomized trial is needed to address the necessity of ACD with or without fusion.

\section{References}

1. Abd-Alrahman N, Dokmak AS, Abou-Madawi A (1999) Anterior cervical discectomy versus anterior cervical fusion, clinical and radiological outcome study. Acta Neurochir 141(10):1089-1092

2. Anderson DG, Albert TJ (2002) Bone grafting, implants, and plating options for anterior cervical fusions. Orthop Clin North Am 33(2):317-328

3. Aronson N, Filtzer Dl, Bugan M (1968) Anterior cervical fusion by the Smith-Robinson approach. J Neurosurg 29:397-404

4. Bartels RH (2005) Single-blinded prospective randomized study comparing open versus needle technique for obtaining autologous cancellous bone from the iliac crest. Eur Spine $\mathbf{J}$ 14(7):649-653

5. Bartels RH, Donk R (2005) Fusion around cervical disc prosthesis: case report. Neurosurgery 57(1):E194

6. Baskin DS, Ryan P, Sonntag V, Westmark R, Widmayer MA (2003) A prospective, randomized, controlled cervical fusion study using recombinant human bone morphogenetic protein-2 with the CORNERSTONE-SR allograft ring and the ATLANTIS anterior cervical plate. Spine 28(12):1219-1225

7. Bolini G, Docquier PL, Viehweger E, Launay F, Jouve JL (2006) Thoracolumbar hemivertebrae resection by double approach in a single procedure: long term follow-up. Spine 31(15):1745-1757

8. Bryan VE Jr (2002) Cervical motion segment replacement. Eur Spine J 11(suppl):92-97

9. Caspar W, Geisler FH, Pitzen T, Johnson TA (1998) Anterior cervical plate stabilization in one- and two-level degenerative disease: overtreatment or benefit? J Spinal Disord 11:1-11

10. Cloward RB (1958) The anterior approach for removal of ruptured cervical discs. J Neurosurg 15:602-617
11. De la Torre M, Martinez-Quinones JV, Isla A, Arguello C, Bendala A, Casado J, Blazquez MG (1995) Anterior cervical discectomy with and without bone grafting. Multicentric comparative study. J Bone Joint Surg Br 77B(Suppl 1):24

12. Dowd GC, Wirth FP (1999) Anterior cervical discectomy: is fusion necessary? J Neurosurg 90(1):8-12

13. Fairbank JC, Couper J, Davies JB, O'Brien JP (1980) The Oswestry low back pain disability questionnaire. Physiotherapy 66:271-273

14. Fu TS, Lai PL, Tsai TT, Niu CC, Chen LH, Chen WJ (2005) Long-term results of disc excision for recurrent lumbar disc herniation with or without posterolateral fusion. Spine 30(24):2830-2834

15. Gelalis ID, Stafilas KS, Korompilias AV, Zacharis KC, Beris AE, Xenakis TA (2006) Decompressive surgery for degenerative lumbar spinal stenosis:long-term results. Int Orthop 30(1):59-63

16. Goffin J, Casey A, Kehr P, Liebig K, Lind B, Logroscino C, Pointillart V, Van Calenbergh F, van Loon J (2002) Preliminary clinical experience with the Bryan Cervical Disc Prosthesis. Neurosurgery 51:840-845

17. Hacker RJ, Cauthen JC, Gilbert TJ, Griffith SL (2000) A prospective randomized multicenter clinical evaluation of an anterior cervical fusion cage. Spine 25(20):2646-2655

18. Hankinson HI, Wilson CB (1975) Use of the operating microscope in anterior cervical discectomy without fusion. J Neurosurg 43:452-456

19. Hillibrand AS, Robbins M (2004) Adjacent segment degeneration and adjacent segment disease: the consequences of spinal fusion? Spine J 4(6):190S-194S

20. Jacobs WCH, Anderson PG, Van Limbeek J, Willems PC, Pavlov P (2004) Single or double-level anterior interbody fusion techniques for cervical degenerative disc disease. Cochrane Database Sys Rev 4:CD 004958

21. Johnson JP, Lauryssen C, Cambron HO, Pashman R, Regan JJ, Anand N, Bray R (2004) Sagittal alignment and the Bryan cervical artificial disc. Neurosurg Focus 17(6):E14

22. Johnson MG, Fisher CG, Boyd M, Pitzen T, Oxland TR, Dvorak MF (2004) The radiographic failure of single segment anterior cervical plate fixation in traumatic cervical flexion distraction injuries. Spine 29(24):2815-2820

23. Kaiser MG, Haid RW, Subach BR, Barnes B, Rodts GE (2002) Anterior cervical plating enhances arthrodesis after discectomy and fusion with cortical allograft. Neurosurgery 50:229-236

24. Kawakami M, Tamaki T, Ando M, Yamada H, Yoshida M (2002) Relationships between sagittal alignment of the cervical spine and morphology of the spinal cord and clinical outcomes in patients with cervical spondylotic myelopathy treated with expansive laminoplasty. J Spinal Disord Tech 15(5):391-397

25. Keller TS, Colloca CJ, Harrison DD, Harrison DE, Janik TJ (2005) Influence of spine morphology on intervertebral disc loads and stresses in asymptomatic adults:implications for the ideal spine. Spine J 5(3):297-309

26. LaFuente J, Casey ATH, Petzold A, Brew S (2005) The Bryan cervical disc prosthesis as an alternative to arthrodesis in the treatment of cervical spondylosis. J Bone Joint Surg 87-B:508-512

27. Lofgren H, Johannsson V, Olsson T, Ryd L, Levander B (2000) Rigid fusion after Cloward operation for cervical disc disease using autograft, allograft, or xenograft: a randomized study with radiostereometric and clinical follow-up assessment. Spine 25(15):1908-1916

28. Madawi AA, Powell M, Crockard HA (1996) Biocompatible oesteoconductive polymer versus iliac graft. A prospective 
comparative study for the evaluation of fusion pattern after anterior cervical discectomy. Spine 21(18):2123-2139

29. Martins AN (1976) Anterior cervical discectomy with and without interbody bone graft. J Neurosurg 44:290-295

30. McConnel JR, Freeman BJ, Debnath UK, Grevitt MP, Prince HG, Webb JK (2003) A prospective randomized comparison of coralline hydroxyapatite with autograft in cervical interbody fusion. Spine 28(4):317-323

31. Morpeth JF, Williams MF (2000) Vocal cord paralysis after anterior cervical discectomy and fusion. Laryngoscope 110(1):43-46

32. Pickett GE, Mitsis DK, Sekhon LH, Sears WR, Duggal N (2004) Effects of a cervical disc prosthesis on segmental and cervical spine alignment. Neurosurg Focus 17(3):E5

33. Robinson RA, Smith GW (1955) Anterolateral cervical disc removal and interbody fusion for cervical disc syndrome. Bull John Hopkins Hosp 96(Suppl):223-224

34. Robinson RA (1964) Anterior and posterior cervical spine fusion. Clin Orthop 35:34-62

35. Rosenorn J, Hansen EB, Rosenorn MA (1983) Anterior cervical discectomy with or without fusion: a prospective study. J Neurosurg 59(2):252-255

36. Savitz MH (2000) Anterior cervical discectomy without fusion or instrumentation: 25 years' experience. Mount Sinai J Med 67(4):314-317

37. Savolainen S, Rinne J, Hernesniemi J (1998) A prospective randomized study of anterior single-level cervical disc operations with long-term follow-up: surgical fusion is unnecessary. Neurosurgery 43(1):51-55
38. Smith GW, Robinson RA (1958) The treatment of certain cervical-spine disorders by anterior removal of the intervertebral disc and interbody fusion. J Bone Joint Surg 40:607-624

39. Sonntag VK, Klara P (1996) Controversy in spine care: is fusion necessary after anterior cervical discectomy? Spine 21:1111-1113

40. Troyanovich SJ, Stroink AR, Kattner KA, Dornan WA, Gubina I (2002) Does anterior plating maintain cervical lordosis versus conventional fusion techniques? A retrospective analysis of patients receiving single-level fusions. J Spinal Disord Tech 15:69-74

41. Vaccaro AR, Singh K, Haid R, Kitchel S, Wuisman P, Taylor W, Branch C, Garfin S (2003) The use of bio-absorbable implants in the spine. Spine J 3(3):227-237

42. Vernon H, Mior S (1991) The neck disability index:a study of reliability and validity. J Manipulat Physiol Ther 14(7):409-415

43. Young WF, Rosenwasser RH (1993) An early comparative analysis of the use of fibular allograft versus autologous iliac crest graft for interbody fusion after anterior cervical discectomy. Spine 18(9):1123-1124

44. Yue WM, Brodner W, Highland TR (2005) Long-term results after anterior cervical discectomy and fusion with allograft and plating:a 5- to 11-year radiologic and clinical follow-up study. Spine 30(19):2138-2144

45. Zoega B, Karholm J, Lind B (2000) Plate fixation adds stability to two-level anterior fusion in the cervical spine. A randomized study using radiosterometry. Eur Spine J 7(4):302-307 